\title{
ON THE TRANSFORMATION OF RESEARCH ON TEACHING AND LEARNING ABOUT THE SUB-MICRO WORLD IN CHEMISTRY EDUCATION INTO FEASBALE CLASSROOM PRACTICE
}

Ingo Eilks

University of Bremen

\begin{abstract}
Absract Along two cases, this paper provides insights into therelationship between empirical research in chemistry education and innovations in classroom practices. The example is teaching and learning about the particulate nature of matter. The paper describes the need for innovation in chemistry classrooms justified by a study based on 28 interviews with experienced chemistry teachers. These interviews covered the teachers' personal practices for how to deal with sub-microscopic concepts in lower secondary school chemistry education. The study revealed that the teaching approaches operated by the teachers in Germany often represent inconsistencies in both teachers' knowledge base and PCK. This paper then contrasts the results with insights into a 15-year classroom innovation and continuous professional development project based on Participatory Action Research in which a group of teachers accompanied by university educators developed an alternative approach for dealing with submicroscopic concepts. This approach is characterized by a coherent curricular structure for dealing with the particulate nature of matter, atomic structure and bonding theory during the whole course of lower secondary chemistry classes.
\end{abstract}

\section{Introduction}

This paper starts from the suggestion that the teacher is one of the key factors for any sustainable innovation in the science classroom (Anderson \& Helms, 2001). It looks at the teachers when it comes to teaching about the different levels and models of the submicroscopic world. Relating macroscopic phenomena to model explanations on the submicro level is suggested to be important since it is one of the essential ideas of modern chemistry (J ohnstone, 1991). However, research in science education from the last 30 years clearly indicates that this task is not easily achieved. A wide variety of conceptual gaps in students' understanding of the sub-micro level have been identified, e.g. understanding the concept of matter as such (Krnel, Watson \& Glazar, 1998), particle interpretations of chemical phenomena (Garnett, Garnett \& Hackling, 1995), chemical reactions (Andersson, 1990), or bonding theory (Hofstein, Levy Nahum, Mamlok-Naaman \& Taber, 2010).

In this paper, the question of teachers' prevalent practices in teaching about the submicro world and the search for better teaching strategies is approached by discussing two different projects (Eilks, 2013). The first project is an explorative study on the beliefs of 28 experienced chemistry teachers, which investigated how experienced teachers in Germany generally suggest to teach the particulate nature of matter via atomic structure to finally arrive at bonding theory (Bindernagel \& Eilks, 2009). Typical pathways German chemistry teachers commonly use throughout the entire lower secondary chemistry curriculum (grade 
5-10, age 10-16) wereidentified to map out available teaching approaches and corresponding effects. This explorative study will be contrasted with a second project consisting of over a decade of Participatory Action Research (Eilks, 2002). This second case is a collaborative research and curriculum development project by a university science educator and a group of teachers focusing the evidence-based development of new teaching and learning approaches for the particulate nature of matter, atomic structure, and bonding theory. The project designed a different approach in the secondary chemistry curriculum, which aims to produce an overarching, coherent structure when dealing with sub-microscopic concepts (e.g. Eilks, 2002, 2013; Eilks \& Möllering, 2001; Eilks, Möllering \&Valanides, 2007).

\section{German chemistry teachers' pathways through the sub-micro world}

The study on German chemistry teachers' suggestions of how to teach the particulate nature of matter and corresponding concepts was part of a project of research-oriented learning in chemistry teacher education (Bindernagel \& Eilks, 2009; Eilks, 2013). The project was conducted at the University of Bremen, Germany, in the years from 2006 and 2009. Research-oriented learning in teacher education in this project was understood as a way for student teachers to participate in empirical research as part of their university teacher education program. Involving student teachers into research projects was thought to give them a better understanding of their field of expertise. It introduced them to education as a field of professional and research-based practice. But, it also aimed at initiating the student teachers' thinking about methodological and epistemological questions in terms of the research base of domain-specific educational fields. In general, research-oriented learning in teacher education also proved to be linked with intrinsic motivation, social sensibility, cooperative attitudes, and the ability to communicate (Wildt, 2006; Kansanen, 2006).

In the courses at the University of Bremen, we combined empirical research with authentic, personal involvement of student teachers with experienced teachers. Searches of existing literature sources were coupled with personal creation of evidence gained in smallscale, individual research. We suggested the mix of personal involvement with original research literature, plus individual data collection and interpretation to provide a fruitful combination, which gives student teachers insights into the objectives, methods, potentials and limitations of science education research (Bindernagel \& Eilks, 2009).

The courses were visited by fourth year university student teachers of chemistry. The goal of these seminars was to arrive at research-based structures for chemistry lessons. The group task given to the students was to develop lessons for junior high school chemistry dasses. The student teachers could freely opt for three different topics: (I) the introduction of a first particle concept, (II) addressing the first particleinterpretation of chemical reactions, or (III) introducing basic atomic structure and bonding. 
The student teachers were asked to use three major sources of information for the lesson planning: empirical research reported in research papers, curriculum development as represented in school textbooks and teacher journals, and classroom practice. The student teachers were asked to compare and combine knowledge from all the three domains. For empirical research evidence the student teachers worked with original papers and reviews concerning students' alternative frameworks and learning difficulties. School textbooks or science teachers' journals were searched for suggestions for well working curricula, experiments and activities. The student teachers were sensitized to the quite often missing reference of the curriculum materials and teacher journals towards the research literature. The student teachers were asked to analyze textbook illustrations and Internet resources, which explicitly illustrate commonly known misconceptions and learning difficulties of students, as described e.g. in Eilks (2003), Eilks et al. (2007) or Eilks, Witteck and Pietzner (2009), in relation to corresponding research evidence (Figure 1).
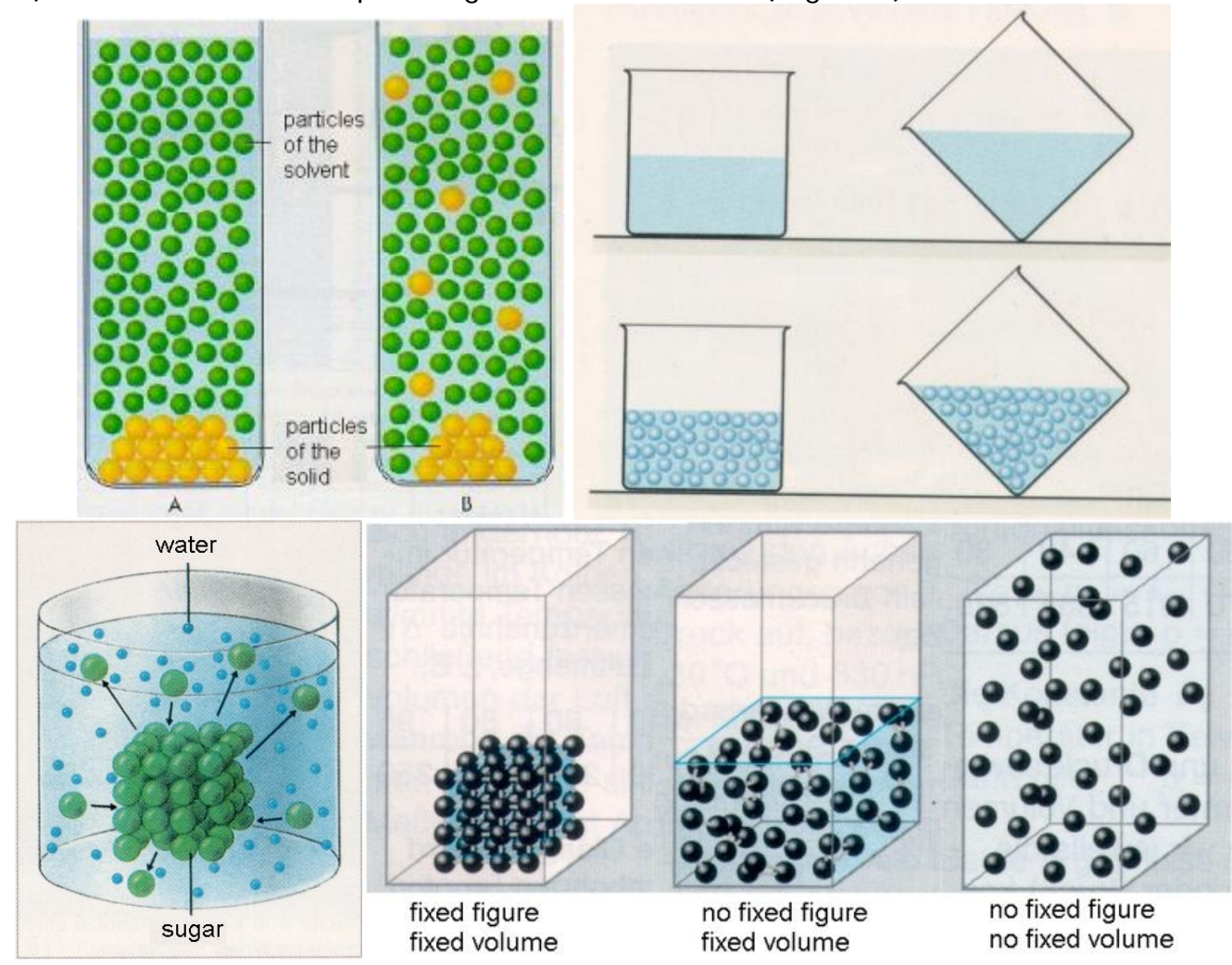

Figure 1 Figures from German school science textbooks: (1) Dissolution: Particles of the solvent and the solid swim in a blue continuum; (2) Behaviour of liquids: Particles swim in a blue continuum and the continuum causes the effect; (3) Dissolution: Only a few water particles swim in a lot of a blue continuum, particle distance in the liquid state is wrong too; (4) States of matter: Distance of particles on the liquid is displayed as a mean between solid and gaseous state (cf. Eilks, 2003).

Despite the growing literature on teachers' PCK, the field of classroom practice concerning the particulate nature of matter in German chemistry teaching was considered being a field which lacks information both in written or printed form. That is why the student teachers in this particular area were asked to create their own research-based resource by interviewing experienced teachers. Fifty-six student teachers from two academic years participated in the 
course, during which 28 experienced chemistry teachers were interviewed. Each interview was conducted by pairs of two student teachers to inspire a friendly atmosphere of discussion, mirroring the situation in which an experienced teacher coaches younger colleagues in the workaday world of school (Bindernagel \& Eilks, 2009).

Teachers were randomly selected from schools by the student teachers. Most of the teachers ranged between 40 and 60 years old. Twenty-five of them had more than five years of practical experience in chemistry teaching. Interviews were conducted along an interview guide that was provided to the student teachers. The guide included questions about teaching strategies in each of the three relevant issues (the particulate nature of matter, chemical reactions, atomic structure and bonding), including queries about personal teaching experiences and the use of specific "sub-microscopic" illustrations extracted from textbooks, like the ones presented in Figure 1. All interviews lasted roughly 45 minutes and were audiotaped and later transcribed.

During the seminar, the student teachers started analyzing the interview data. The student teachers gave short presentations on their interviews, using the structure of the interview guide as a map. The student teachers illustrated their findings and interpretations with the most impressive teacher quotes which they found in the data. In parallel with the seminar, a detailed analysis of the data began. This analysis focused mapping the teachers' curricular approaches when dealing with the different sub-microscopic concepts over the course of lower secondary school lessons (Bindernagel \& Eilks, 2009). This analysis was carried out using qualitative content analysis (Mayring, 2000). The findings were later transferred into a graphic mapping of pathways suggested by the teachers. A second analysis focused teachers' understanding of the nature models and modeling when explaining teaching approaches on the particulate nature of matter. For this part of the analysis, an evaluation grid was developed which was inspired by Grosslight, Unger, Jay, and Smith (1991). This aspect will not be discussed further in this paper. For the results of this study, see either Sprotte and Eilks (2007) or Bindernagel and Eilks (2008).

Figure 2 provides a mapping of the pathways suggested by 28 experienced German chemistry teachers concerning the teaching of the particulate nature of matter in the lower secondary level. The boxes in the graph represent the different sub-microscopic models the teachers touched upon in their interviews. For a detailed description of the different models see Eilks (2013).

In accordance with the traditionally-used, content-oriented structure of most German curricula, we can recognize three different levels: (I) a level of simple discrete particles, (II) a level of atoms and atomic structure, and (III) a level of bonding and molecular structure. The lines in Figure 2 represent connections between the models and the respective numbers of teachers choosing a particular path from one model to another (Bindernagel \& Eilks, 2009). 


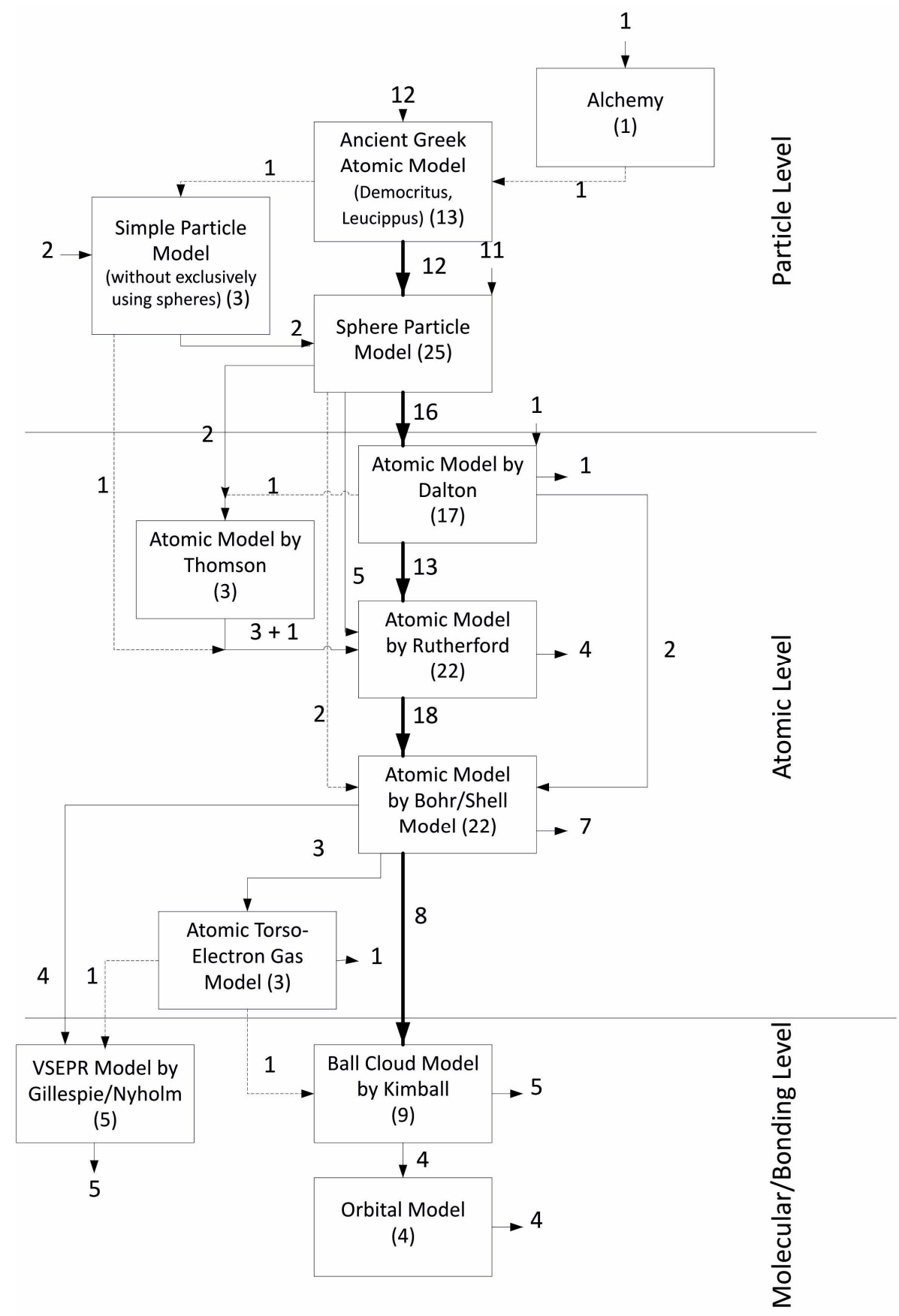

Figure 2 Teaching pathways for 27 of the 28 teachers. One of the teachers professed that he exclusively is using project-based learning and thus not having a conceptualized structure related to teaching the particulate nature of matter (Bindernagel \& Eilks, 2009).

All but one of the teachers approached the sub-microscopic level by introducing a simple model of discrete particles. This is in line with most of the official syllabi in the different German States (the 'Länder'). Half of the teachers suggested a historical approach when moving towards the particle level and referred to the ancient Greek philosophers. This decision is not based on the syllabi, it was a decision made by these teachers. Others suggested a more pragmatic approach stemming from phenomena without referring to the history of chemistry. 
Nearly all of the teachers introduced a simple particle model at this point, in which particles are represented as hard spheres. Only three of the 28 teachers do not present the sphere model in their lessons or vary their pictorial representations of particles in their illustrations although around that time there was an extremely controversial debate in various German-language chemistry teacher journals. In that discussion, it was suggested not choosing spheres as a standard tool, but rather representing discrete particles by various physical shapes. This was done to avoid mixing up different models. Two reasons were given based on evidence: First, not exclusively using spheres for discrete particles has proved itself useful in avoiding confusion among learners when it comes to changing from the level of discrete particles to the level of atoms. Second, the widely-varying shapes make it explicitly clear to pupils that a model is being used. The vast majority of teachers seemed to be totally unaware of this debate.

Generally in their advice, most in-service teachers suggested introducing sub-micro level chemistry based on the history of science. This was explicitly stated by 22 out of 28 of the participants. They suggested a variation in models to structure the chemistry curriculum, starting for example with a simple particle model, via the Dalton atomic model, towards different models of atomic structure and of bonding theory. These last steps should be operated using models ranging from the historical ideas of Rutherford, Thomson and Bohr, followed up with models of bonding, the VSEPR-model, or orbital theory.

While explaining their teaching strategy, several teachers mixed up different models. They either combined them into hybrid-models (Justi \& Gilbert, 2002) or did not differentiate sufficiently clear between them. This happened especially in mixing up the sphere model of discrete particles and the Dalton atomic model:

You mean another particle model? I wouldn't know of any other. Yes, I always say particle, but that is the Dalton model, right? I don't call it that, but that is the model actually. The atoms are small, compact spheres like billiard balls.

It turned out that many teachers were not aware of the basic differences between the sphere model of discrete particles referring to kinetic gas theory, any ancient Greek particle model, or the Dalton atomic model. In these teachers' minds, their teaching approach seems to accurately represent the history of science, many teachers would not deviate from this approach.

At the beginning of 8th grade, the sphere particle model, followed by the Dalton model in the middle or at the end of the year. 9th grade Rutherford, in the 10th grade or maybe the end of 9th grade, Bohr's model. In 10th grade we use the electron ball cloud model, which is of course a kind of orbital model and also lends itself as a model for chemical bonding......You can pretty much forget the Bohr model. Although substances' color can be satisfactorily described with it.....You always have to roll out a model whenever you want to explain something. This means following the historical development of models. That's the sameorder (that the models were developed in). This fits the pattern of teaching. I wouldn't want to deviate from it. 
The history-driven approach seems to be somewhat self-evident to the teachers, they called it the 'classical approach':

It is such a classical approach just at this point, where one moves from Dalton's atomic model to Thomson's watermelon model and then on to Rutherford's model.

Most teachers described use of three to seven different models for the sub-micro world just for the junior high school cycle. Some of the interviews give the impression that the more models the teachers use the more often connections between them start getting to be somewhat confusing:

It naturally starts somewhere with Dalton and then, Rutherford, Dalton, then eventually you end up at Bohr's atomic model.....in order to explain certain basic concepts. There's always a big fight, I think, about whether Bohr's atomic model is very limited or not and that we should bring in the orbital model somewhere..... I usually stay with the Bohr model, in any case for the basics I stop there........definitely, becauseyou can use it well for the electron pair repulsion model, then yes. You can theoretically show the spatial structure of compounds or electron bonding........Now I have to mention Democritus, maybe it's tied to such a term. At the very beginning comes the particle idea - spherical particles, but that doesn't have to do with the atomic model...

The number and selection of models varies. Nevertheless, there were some points of common agreement. This included use of the Dalton, Rutherford and Bohr atomic models reaching a state of an atom to be composed of nucleus and shells.

I like to use the nucleus-shell model. I find that Rutherford and his idea are actually very important. I try to make this evident - I hit against objects and such, as if it is unfathomable that there isn't supposed to be anything there. [The teacher smacks his hand against the wall as he explains this] So developing this belief that something is solid and yet composed of almost nothing is really difficult to bring across and, in effect, you can only try to make it interesting and to prepare yourself so that you maybe succeed by using anecdotes. And the gold foil is naturally somehow the key.

A sound justification for choosing the history-driven approach was only given by a minority of the teachers. Those few teachers actually naming reasons referred to the objectives of teaching about the nature of scientific models. They argued that students by this approach learn about their tentative nature:

That's something that Dalton's model doesn't explain; instead you need a differentiated atomic model. OK, when the pupil reaches this point and says: We can't explain the phenomenon, with which we are currently faced, by using any model concepts that we already know. The modeling idea doesn't hold up and isn't differentiated enough. And then we continue just like scientists and look in the literature. What do we find there? What did other clever people from long ago find there? Then I introduce the Rutherford model.

Evidence of the historical approach's success on learning about both the particulate nature of matter and the nature of models and modelling was not discussed; the teachers view appeared more to have some kind of a paradigmatic character. Combining this viewpoint 
with the teachers' ability to clearly distinguish between different models, including their professed understanding of the nature of scientific models and the history of science (Sprotte \& Eilks, 2007; Bindernagel \& Eilks, 2008) suggests to become sceptic to whether this approach works in practice. Success seems to be dubious when we consider that these teachers sometimes (I) do themselves have not a very well-developed understanding of the nature of scientific models, (II) are not able to distinguish and clearly explain the history of the different sub-microscopic models, (III) cannot provide any clear pedagogical justification for switching between up to seven different models, and (IV) are unable to explain this strategies well justified to younger colleagues.

Three out of the 28 teachers did not use the history-driven approach to structure their curriculum. Part of this group suggested a curricular approach oriented around meaningful contexts, the applications of chemistry, and a project-based learning approach. Two of them stated that there should be a search for internally coherent conceptual development. In their view, switching between different historic models reduces most students' motivation, because they do not understand the differences and contradictions between the models and do not have the necessary skills to develop meta-cognitive strategies for dealing with them. The remaining three teachers mentioned not being satisfied with the history-driven approach, but they had not found or could imagine any alternate curriculum approach so far.

\section{Development of a changed teaching strategy for the sub-micro world}

By the year 2000, a group of researchers and practitioners had initiated a project of Participatory Action Research in chemistry education as suggested by Eilks and Ralle(2002). The project addresses 'New ways towards the particle concept' (Eilks \& Möllering, 2001). Participatory Action Research (PAR) in science education is a cyclical process of curriculum innovation and classroom-based research in a partnership of practicing teachers and science educators. The foci and initiatives towards practice improvement are negotiated jointly by all the persons involved. For collaboration the PAR groups meet about once a month for discussion, work on classroom materials and exchange of experiences or accompanying research findings. Both empirical research evidence as well as classroom experience and teacher intuition provide the base for collaborative curriculum development and classroombased research (Figure 3). Objectives enoompass creating knowledge about teaching and learning, developing the curriculum with development of corresponding teaching and learning materials, practice improvement, as well as teacher continuous professional development (Mamlok-Naaman \& Eilks, 2012). Central elements of the developmental strategy are a permanent contrasting of available research findings and teachers experiences in group discussions as well as a cyclical strategy for development informed by evaluation from multiple perspectives (Eilks \& Ralle, 2002). 


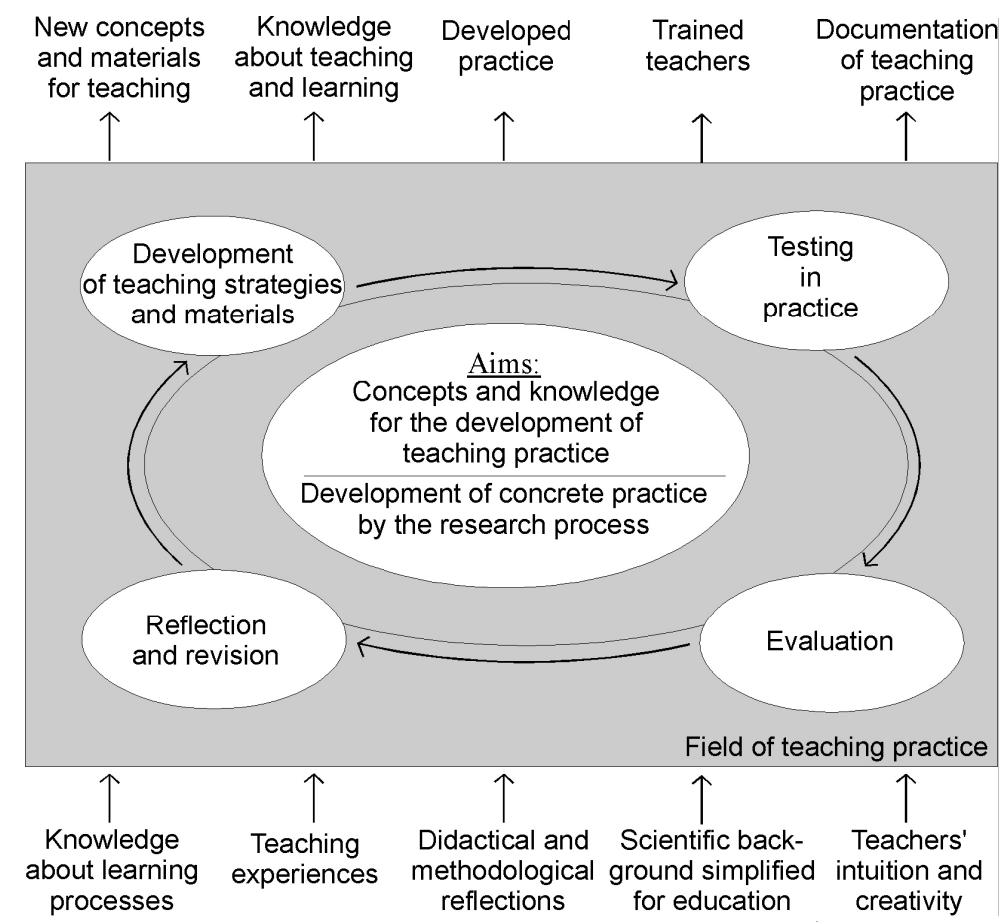

Figure 3 Participatory Action Research in science education (Eilks \& Ralle, 2002)

The group of teachers and chemistry educators in this project decided to focus curriculum development and classroom-based research on teaching and learning about the submicroscopic world. The work was inspired by the increasing awareness of several group members of the incomprehensible breaks and barriers extant in the history-driven approach in the chemistry curriculum. The teachers got aware that this has particularly an effect on younger pupils (age 12-16) when they are confronted with a multitude of different models. From the teachers' point of view, these learners generally have neither an intrinsic motivation to understand exactly why model switches are necessary, nor in most cases developed metacognitive competence which is up to the task of reflecting upon the inherently tentative nature of models.

The central objective of the project was the design and development of an innovative and effective teaching strategy for dealing with the particulate nature of matter in lower secondary chemistry teaching (Eilks \& Möllering, 2001; Eilks et al., 2007). This approach targets the development of lesson plans, the application of cooperative learning strategies, and the integration of ICT into teaching and learning. However, the central idea was the development of an internally coherent conceptual structure of teaching sub-microscopic concepts in chemistry. The idea was a curriculum without any conflicts stemming from contradictions within its different parts. It was suggested that such an approach might allow students to better learn sub-microscopic concepts and leave learning about the tentative nature of models in another position in the curriculum (Eilks, 2002; 2013).

The design process was accompanied by various initiatives for evaluating the effectiveness of the altered teaching strategy. The evaluation focused on learners' motivation, achievement and understanding. It focused also the feasibility of the changed teaching strategy, 
considering the views from both the pupils and teachers perspectives (e.g. Eilks, 2005). Interviews with students (e.g. Eilks et al., 2007), analysis of artifacts, and written tests were also used (e.g. Eilks, 2005). Classroom observations, teacher feedback, and group discussion were used to gain a comprehensive picture. All the information was used for cyclically refining the classroom activities, but also to map the effects on teachers' professional development (Eilks \&Markic, 2011).

In the beginning of the project the teachers described that they generally face problems when teaching the particulate nature of matter, and research confirmed the persistence of many of their perceived problems in this area. From the teachers' viewpoint, the many suggested sub-micro models often are insufficiently presented by textbooks and in class. These points came up in the initial meetings of the PAR group and stemmed from the individual teachers' reflection. However, the study reported above suggests that this might be a much more general problem in Germany's commonly-applied curricula. A parallel analysis of German textbooks has also indicated that most common teaching concepts are often inconsistently and unclearly differentiated from the perspective of using different models. Some of theinconsistencies in the chemistry textbooks even resemble those reported in the literature concerning students' inattentiveness in model use. Some textbooks seem to both perpetuate the common misconceptions spread among the students and create even more (Eilks, 2003).

From this starting point, the PAR group decided to work out a new curriculum approach for sub-microscopic concepts which is internally consistent. The group hoped to find a way to avoid gaps in student learning caused by the repeated switching from one model to another. The new approach, however, was suggested not only to be internally coherent, but also as scientifically aoceptable and compatible with students' learning capabilities, too. A similar idea had been proposed in 1996 by de Vos and Verdonk, however their concept was only worked out for a few initial steps. The aim of this project was to develop a coherent, welltuned didactic sequence (including lesson plans and materials) for effectively teaching the particulate nature of matter in the entire lower secondary curriculum. The main guiding principle was developing students' knowledge over different stages without introducing contradictions to previously-introduced models.

One example might illustrate the inconsistencies in previous curricula. Generally, a first particle model of the sub-micro level is introduced using spheres to represent discrete particles (see above). The spheres in such models stand for all discrete particles as either molecules, ions (both mono- and multi-atomic); or they do represent atoms in inert gases and metals. However, students at a later stage often face lasting difficulties in distinguishing such particles from their constituent entities, theatoms. Atoms are normally also represented using spheres when using the Dalton atomic model. Teachers need to - but are not always able to - make a clear distinction between discrete particles and atoms (Hesse \& Anderson, 1992). Their students are quite often unable to make this clear distinction, thereby facing many difficulties. These difficulties have wide-reaching implications for students' later 
understanding of the chemical reaction. In several German chemistry textbooks chemical reactions are introduced as a "rearrangement of particles". However, some of these textbooks do not clearly change from the level of discrete particles towards the level of atoms (Eilks, Leerhoff \& Möllering, 2002; Eilks et al., 2007). Therefore, students attempt to rearrange simple discrete particles to explain chemical reactions. Consequently, there is no clear distinction between chemical reactions and processes of dissolution or diffusion (or just mixing). The reason is that the sphere-model of discrete particles does not facilitate the explanation of substance changes during chemical reactions (Figure 3). The model does not allow for the composition of a pure substance as the product of a reaction between two initial substances, since such a product must be constructed (within this model) of identical spheres representing the particles of the product, something the model does not allow. Additionally, the reaction from one initial substance into two or more products is also not possible (in Figure 4 this would be the reverse reaction). In this case, we should have one kind of identical spheres at the beginning, and two or more kinds of particles after the completion of the reaction. This cannot be explained by any kind of 'rearrangement' (Eilks et al., 2007, Eilks, 2013).

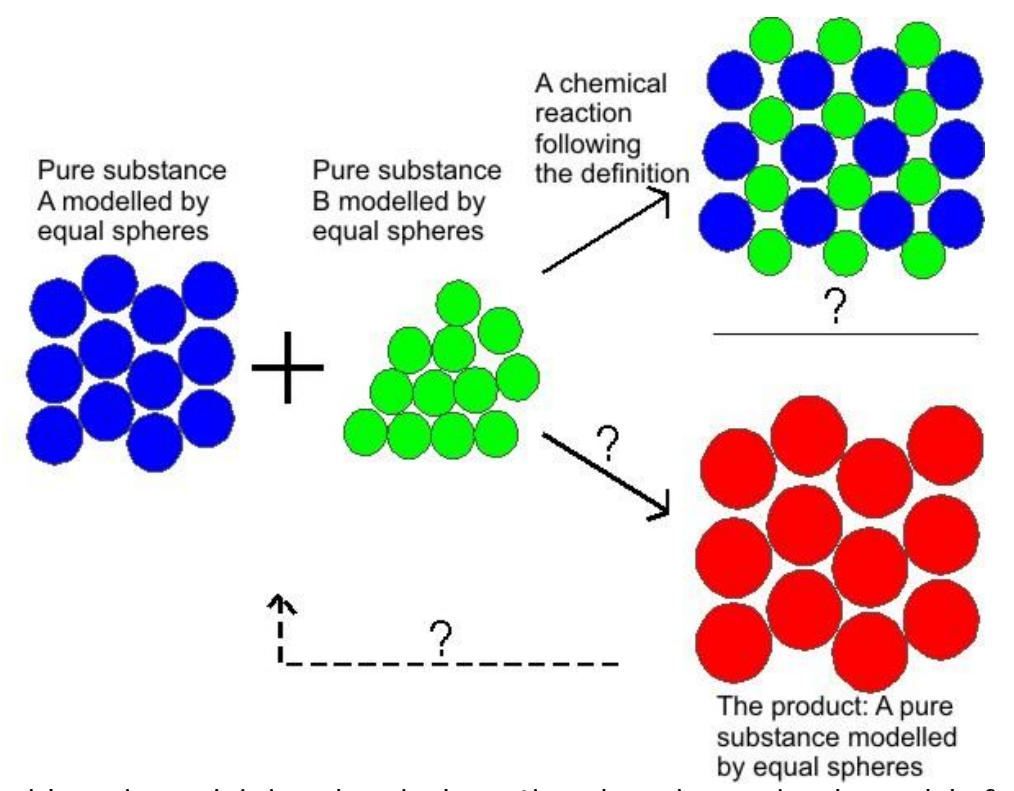

Figure 4 Problems in explaining chemical reactions based on a simple model of spheres representing discrete particles (Eilks et al., 2007)

The participants in this action research group strongly believe that there is no need to introduce a 'model of discrete particles to be represented by spheres' as suggested by most German textbooks. The group preferred the introduction of a 'model consisting of discrete particles of different form and size'. The example is only a small part of the entire process and resulting structure. For more details see e.g. Eilks et al. (2007), Eilks (2005), or Eilks (2013).

Finally the PAR group over the time of about five years, developed an outline for a curricular framework, which (I) fits the objectives of the project, (II) meets the governmental 
guidelines outlined in the syllabi, and (II) starts curriculum structuring from a thorough analysis of students' misconceptions and learning impediments. In the end, an outline of key sentences was suggested as guidance for internally-coherent teaching approaches. The approach tries to be as simple as necessary and to use as few as possible information and complexity; but nevertheless it is sufficient to explain all sub-micro related topics of the entire lower German chemistry curriculum. The first step closely parallels the approach suggested by De Vos and Verdonk (1996). The key sentences are outlined in Figure 5 to 8 (cf. Eilks, 2002; 2013).

- All matter consists of small particles.

- All these small particles do have some mass. But, one never can see the small particles with the eyes, not even with the best microscopes. Nevertheless, a scanning tunneling microscope can make pictures of the small particles.

- $\quad$ Nothing exists between the small particles.

- The small particles are in constant motion. With a rise in temperature their average motion increases; with a fall in temperature their average motion decreases. At constant temperature the average motion of the small particles stays constant.

- Collision of two small particles occurs in a fashion where both particles maintain their kinetic energy.

- $\quad$ Between the small particles, forces of attraction and repulsion exist, which are strongly dependent on the distance between the particles.

- We can explain many different phenomena with the help of these key sentences on the structure of particulate matter. But we still can't draw any conclusions about the actual appearance of the particles. For such conclusions, we would need more information about both the individual building units composing the small particles and their inner structure.

Figure 5 Key sentences at the discrete particle level

- The smallest particles out of which all substances are built from one or more types of building units called atoms.

- Atoms are spherical and are composed of a nucleus and one or more electron shells. The diameter of the nucleus is only about $1 / 10,000$ to $1 / 100,000$ of the total atomic diameter. The nucleus contains almost the entire mass of the atom.

- Atoms are made up of protons, neutrons and electrons. In an electrically neutral atom, the total number of protons equals the total number of electrons.

- The nucleus contains the protons and neutrons. Protons are positively charged, neutrons are neutral. Atomic nuclei are not changed by chemical reactions or electrical processes. Nuclei only change through radioactive decay, nuclear fission or nuclear fusion.

- The electron shells contain electrons, which move both inside the atom and - under certain conditions - between atoms. Electrons are negatively charged. They are found in differing energy levels within the electron shell. We can imagine that these levels form several shells at varying distances from the nucleus. The innermost shell can hold 2 electrons, the next two 8 , and the fourth 18. It is impossible to say exactly where a given electron is inside the shell at any given moment. Atoms with the same electron configuration in their outermost shell as the noble gases ( 8 electrons or an "octet") are especially stabile.

- Each of the more than 100 chemical elements has a characteristic number of protons in the nucleus. It is possible for the number of neutrons in the nucleus to vary among atoms of the same element. In this case we call them isotopes of this element.

Figure 6 Key sentences at the atomic structure level 
There are three different classes of chemical bonds:

a) Ionic bonds: Ionic bonds form between anions (negatively charged particles) and cations (positively charged particles), which attract one another electrostatically due to their opposite charges. This attraction works on all directions equally. The structure of ionic substances, also called salts, arises at the particle level through the packing together of the ions based on their size and shape.

b) Metallic bonds: Metallic bonds occur between metal atoms. These atoms in a metallic structure are unable to donate electrons to a specific partner or to accept electrons from same in order to achieve the noble gas configuration. For this reason, the electrons in the outermost shell disperse between all of the metal atoms. This is a favorable condition and leads to typical metallic behavior, like good electrical conductivity. The dispersal of electrons is the same in all directions. The structure of substances formed through metallic bonds, also called metals, arises at the particle level through the packing together of the ions based on their size.

c) Covalent bonds (electron pair bonds): Covalent bonds form between atoms which share two electrons in a bond which allows both to achieve the noble gas configuration. The covalent bond lies between both atoms and is said to be "shared". Depending on the type of atoms bound together and their individual ability to attract electrons towards themselves (electronegativity), the electrons in the bond can be skewed in varying degrees towards one of the bonding partners (a polarized bond). The structure of substances formed through covalent bonds arises at the particle level through further rules, which are summed up by the structural concepts describing the various types of covalent bonds.

Figure 7 Key sentences at the level of different types of bonding

- Covalent chemical bonds are made of two electrons, which are located between the two bonded atoms in the form of a bonding electron pair.

- In atoms with more than one bond, the bonds separate themselves spatially, so that they maintain the greatest amount of separation from one another possible.

- In the case of double or triple bonds, the spatial structure of the bond is described as if only a single bond were present.

- If nonbonding electron pairs are present in addition to the covalent bond in the valence shell, they must also be considered. The structure of the resulting molecule must space the bonding and nonbonding pairs of electrons, so that they maintain the greatest amount of spatial separation from one another possible.

- In the simplest cases, the arrangement of the bonds around an atom yields: A linear structure for a total of 2 bonds and/ or nonbonding electron pairs

- A trigonal planar structure for a total of 3 bonds and/ or nonbonding electron pairs

- A tetrahedral structure for a total of 4 bonds and/ or nonbonding electron pairs

- The repulsion of the free electron pairs towards each other and covalent bonding pairs is somewhat larger than repulsion of the covalent bonds towards one another. This can lead to light discrepancies in the expected arrangements between the atoms. Such changes in bonding angles and positioning can also be caused when one of the bonding partners is extremely large or when the bonds are strongly polarized towards one of the partners.

Figure 8 Key sentences for the level of molecular structure

The teaching and learning materials developed in this project have been applied to more than a hundred learning groups by the teachers in the PAR group. From accompanying research (e.g. Eilks, 2005; Eilks et al., 2007) and the feedback provided by the teachers, the approach proved to provide teachers with a finely-tuned and therefore motivating approach. With help of the PAR teachers, the strategy was operated into an entire curriculum published in a series of new textbooks for lower secondary chemistry classes in Germany. The books show that the approach is applicable and reliable for the whole junior high school level (e.g. Eilks \& Bolte, 2008). 


\section{Conclusions}

This paper discusses teaching pathways of experienced German chemistry teachers. It reveals a strong and predominant belief that teaching the sub-microscopic level should follow a sequence of different historic models. However, the suggested teaching strategies are often poorly elaborated and the justification provided for them is rarely reflected upon. The study also shows that teacher content knowledge and their PCK sometimes is lacking in correctness and coherence. Only a very few teachers seem to be aware of the large amounts of empirical evidence available about teaching sub-microscopic concepts and about alternative curricula approaches. Accordingly, most of the teachers do not change their teaching.

Yet the second study shows that systematically used educational evidence of students' alternate conceptions and learning difficulties can lead to constructing an alternative and more efficient curricular structure. The project documents that teaching sub-microscopic concepts properly by using an internally coherent conceptual structure for the whole range of lower secondary science curricula in possible. Evidence is available that application of the alternative curriculum is feasibly and can be successfully carried out in a motivating fashion.

Change in the curriculum is possible. If it uses evidence from research in a systematic way learning difficulties can be reduced. However, also the developmental process can be strengthened when it is based on a sound research strategy, e.g. by Participatory Action Research as suggested by Eilks and Ralle (2002). Thus in the end, the maybe most important message in this paper is to search for more thorough models of bringing empirical research, evidence-based curriculum development and classroom practice together as it was e.g. described as a big demand in chemistry education by De Jong (2000). The here described project and the model of Participatory Action Research in science education might offer a template for future initiatives. 


\section{References}

Anderson, B. (1990). Pupils' conceptions of matter and its transformations (age 12-16). Studies in Science Education, 18, 53-85.

Anderson, R., \&Helms, J . V. (2001). The ideal of standards and the reality of schools: Needed research. J ournal of Research in Science Teaching, 38, 3-16.

Bindernagel, J . A., \& Eilks, I. (2008). Modelle und Modelldenken im Chemieunterricht und ein Einblick in das Verständnis von erfahrenen Chemielehrkräften [Models and thinking in models in chemistry teaching and insights into the knowledge of experienced chemistry teachers]. Chemie konkret, 15, 181-186.

Bindernagel, J . A., \& Eilks, I. (2009). The roadmap approach to portray and develop chemistry teachers Pedagogical Content Knowledge ooncerning the particulate nature of matter. Chemistry Education Research and Practice, 9, 77-85.

DeJ ong, O. (2000). Crossing the borders: chemical education research and teaching practice. University Chemistry Education, 4, 31-34.

De Vos, W., \& Verdonk, A. H. (1996). The particulate nature of matter in science education and in science. J ournal of Research in Science Teaching, 33, 657-664.

Eilks, I. (2002). Von der Rastertunnelmikroskopie zur Struktur des Wassermoleküls - Ein anderer Weg durch das Teilchenkonzept in der Sekundarstufe I (Teil 1 und 2) [From scanning tunneling microsocopy towards the the structure of the water molecule - An alternative way through the particle ooncept in lower secondary teaching (Part 1 and 2)]. Chemie und Schule (Salzbg.), 17 (3), 7-12 and 17 (4), 2-6.

Eilks, I. (2003). Students' understanding of the particulate nature of matter and misleading textbook illustrations. Chemistry in Action, 2003, no. 69, 35-40.

Eilks, I. (2005). Experiences and reflection about teaching atomic structure in a jigsaw classroom in lower secondary level chemistry lessons. J ournal of Chemical Education, 82, 313-320.

Eilks, I. (2013). Teachers' ways through the particulate nature of matter in lower secondary chemistry teaching: A continued change of different models vs. a coherent conceptual structure?. In G. Tsaparlis \& H. Sevian (eds.), Concepts of matter in science education (pp. 213-230). Dordrecht: Springer.

Eilks, I., \&Bolte, B. (Eds.) (2008). Chemie interaktiv (Ausgabe A) [Chemistry Interactive; Issue A] . Berlin: Cornelsen.

Eilks, I., Leerhoff, G., \& Möllering, J . (2002). Was ist eigentlich eine chemische Reaktion? [What in fact is a chemical reaction?]. Der Mathematische und Naturwissenschaftliche Unterricht, 55, 8491.

Eilks, I., \&Markic, S. (2011). Effects of a long-term Participatory Action Research project on science teachers' professional development. Eurasia J ournal of Mathematics, Science and Technology Education, 7, 149-160.

Eilks, I., \&Möllering, J. (2001). Neue Wege zu einem fächerübergreifenden Verständnis des Teilchenkonzepts [New ways towards an inter-disciplinary understanding of the particle concept]. Der Mathematische und Naturwissenschaftliche Unterricht, 54, 421-427.

Eilks, I., Möllering, J., \&Valanides, N. (2007). Seventh-grade students' understanding of chemical reactions - Reflections from an action research interview study. Eurasia J ournal of Mathematics, Science and Technology Education, 4, 271-286.

Eilks, I., \&Ralle, B. (2002). Participatory Action Research within chemical education. In B. Ralle \&I. Eilks (Eds.), Research in chemical education - What does this mean? (pp. 87-98). Aachen: Shaker.

Eilks, I., Witteck, T., \& Pietzner, V. (2009). Using multimedia learning aids from the Internet for teaching chemistry - Not as easy as it seems?. In Susan Rodrigues (Ed.), Multiple Literacy and Science Education: ICTS in Formal and Informal Learning Environments (pp. 49-69). Hershey: IGI Global. 
Garnett, P.J., Garnett, P. J ., \& Hackling, M. W. (1995). Students' alternative conceptions in chemistry: A review of research and implications for teaching and learning. Studies in Science Education, 25, 65-95.

Grosslight, L., Unger, C., J ay, E., \& Smith, C. L. (1991). Understanding models and their use in science: conceptions of middle and high school students and experts. J ournal of Research in Science Teaching, 28, 799-822.

Hesse, J . J . III, \&Anderson, C. W. (1992). Students' conceptions of chemical change. J ournal of Research in Science Teaching, 29, 277-299.

Hofstein, A., Levy Nahum, T., Mamlok-Naaman, R., \&Taber, K. S. (2010). Teaching and learning the concept of chemical bonding. Studies in Science Education, 46, 179-207.

J ohnstone, A. H. (1991). Why is science difficult to learn? Things are seldom what they seem. J ournal of Computer Assisted Learning, 7, 75-83.

Justi, R., \& Gilbert, J. K. (2002). Models and modeling in chemical education. In: J . K. Gilbert, O. de J ong, R. J usti, D. F. Treagust \&J . H. Van Driel (Eds.), Chemical education: towards researchbased practice (pp. 47-68). Dordrecht: Kluwer.

Kansanen, P., (2006), Constructing a research-based program in teacher education. In: F. K. Oser, F. Achtenhagen \&U. Renold (Eds.), Competence oriented teacher training. Old research demands and new pathways (pp. 11-22). Rotterdam: Sense.

Krnel, D., Watson, R., \& Glazar, A. (1998). Survey of research related to the development of the concept of 'matter'. International J ournal of Science Education, 20, 257-289.

Mamlok-Naaman, R., \& Eilks, I. (2012). Action research to promote chemistry teachers' professional development - Cases and experiences from Israel and Germany. International J ournal of Mathematics and Science Education, 10, 581-610.

Mayring, P. (2000). Qualitative content analysis. Forum: Qualitative Social Research, 1(2). Retrieved from the World Wide Web on 01/ 02/ 2002 at www.qualitative-research.net/ fqs.

Sprotte, J. A., \& Eilks, I. (2007). Introducing the particulate nature of matter - Results from a case study on experienced German science teachers' PCK of models and modeling. Paper presented at the 6th Conference of the European Science Education Research Association, Malmoe, Sweden, 21 August - 25 August 2007.

Wildt, J. (2006). Research-oriented learning in teacher education. In: I. Eilks and B. Ralle (Eds.), Towards research-based science teacher education (pp. 5-12). Aachen: Shaker. 